\title{
Diagnostic Accuracy of PCR-Based Detection Tests for Helicobacter Pylori in Otitis Media: A Meta-Analysis
}

\section{Fakher Rahim*}

PhD in Molecular Medicine, Toxicology Research Center, Ahvaz Jundishapur University of Medical Sciences, Ahvaz, Iran

\begin{abstract}
Background and objectives: Helicobacter pylori (H. Pylori) infection has serious consequences such as peptic ulcers and gastric cancer. Histologic identification of organisms remains the gold standard in the diagnosis of $H$. pylori. This meta-analysis reviewed the overall diagnostic accuracy of polymerase chain reaction (PCR) vs histology of $H$. pylori infection in the patients with otitis media with effusion (OME).

Methods: Medline, Scopus and ISI web of science were systematically searched. Articles meeting the selection criteria were retrieved for the data collection and analysis. Diagnostic odds ratio (DOR) and symmetric summary receiver operating characteristic (SROC) of OME -associated .H. pylori infection was estimated for each study. The PCR techniques were compared to the histological tests as the gold standard in diagnosing $H$. pylori infection.

Results: We included eight relevant studies compromising 259 case of OME. The pooled sensitivity and specificity of PCR compared to the histological diagnosis of $H$. Pylori infection in patient with OME were $71 \%(95 \% \mathrm{Cl}$ : $\left.61 \%-80 \%, I^{2}: 0.0 \%\right)$ and $81 \%$ (95\%Cl: $\left.76 \%-86 \%, I^{2}: 59.9 \%\right)$, respectively. Pooled positive likelihood ratio (PLR) and negative likelihood ratio (NLR) for PCR were $3.61\left(95 \% \mathrm{Cl}: 2.34-5.59, \mathrm{I}^{2}: 44.5 \%\right)$ and $0.42(95 \% \mathrm{Cl}: 0.31-0.57$, $\left.I^{2}: 0.1 \%\right)$, respectively. For DOR analysis, the pooled accuracy of PCR was $10.78\left(95 \% \mathrm{Cl}: 5.95-19.53, \mathrm{I}^{2}: 0.0 \%\right)$ in diagnosing $H$. Pylori infection.

Conclusions: This review showed statistically significant differences in the diagnostic accuracy between the PCR and histological tests. This meta-analysis also suggests a higher sensitivity and specificity of PCR-based molecular diagnostic of $H$. Pylori infection in OME patients compared to the histological tests.
\end{abstract}

Keywords: Diagnostic accuracy; Meta-analysis; H. Pylori infection; Otitis media with effusion (OME); Polymerase chain reaction (PCR); Histology

\section{Introduction}

Helicobacter pylori (H. Pylori) infection has serious consequences such as peptic ulcers and gastric cancer [1-3]. Histologic identification remains the gold standard in diagnosing $H$. pylori infection [4]. The urea breath test, polymerase chain reaction (PCR), and CLO are also the most reliable diagnostic techniques for H. Pylori infection [5]. Some researchers reported the association between $H$. pylori infection and upper respiratory diseases, including chronic rhino sinusitis, chronic otitis media, and chronic otitis media with effusion [6-12], but little is known about the true colonization and the localization of these bacteria in the upper respiratory tract tissue.

Otitis media with effusion (OME) is a more common condition in persons with poor Eustachian tube function, in which the pathogenesis still remains unknown. Viral or bacterial infections, autoimmunity, allergy, gastro esophageal reflux possibly play a role in the pathogenesis of OME [13]. Recently, the heritability and genetic determinants of OME were also studied [14,15]. Epidemiological evidences have suggested the possible relationship of $H$. Pylori with the OME [16-18]. Over the last decade, several molecular techniques have been developed for targeting various microbial genes $[19,20]$. Polymerase chain reaction (PCR) is one of the most common molecular techniques used in detecting H. Pylori infection [21-23].To the best of our knowledge, the diagnostic accuracy of PCR-based methods for OME-infected patients has not been systematically reviewed and synthesized. Thus, we conducted a meta-analysis and systematic review to summarize the evidence on diagnostic accuracy of PCR-based tests compared to the histological methods in the patients with OME.

\section{Materials and Methods}

\section{Literature review}

We performed a systematic search without a language limitation in the Medline, Scopus and ISI web of science, covering all published papers up to March 2013, with the following combination of Mesh standardized keywords: (("Helicobacter pylori"[Mesh]) AND ("Otitis Media"[Mesh] OR "Otitis Media with Effusion"[Mesh] OR "Otitis Media, Suppurative"[Mesh])) OR "Otolaryngology"[Mesh]. We reviewed potentially selected publications through titles and abstract screening and then collected the most related publications for a closer evaluation. Besides, the reference lists of the selected papers were also screened for other potential articles that possibly have been missed in the initial search.

\section{Inclusion and exclusion criteria}

The PCR techniques were compared to the histological tests as the gold standard in diagnosing the $H$. pylori infection. Those studies, which concern the association of $H$. pylori infection with OME risk using PCR and histological methods, offer the size of the sample,

*Corresponding author: Fakher Rahim, Toxicology Research Center, Ahvaz Jundishapur University of Medical sciences, Ahvaz, Iran, Tel: +986113367562 E-mail: Bioinfo2003@ajums.ac.ir / F-rahim@Razi.Tums.ac.ir

Received June 20, 2013; Accepted August 05, 2013; Published August 07, 2013

Citation: Rahim F (2013) Diagnostic Accuracy of PCR-Based Detection Tests for Helicobacter Pylori in Otitis Media: A Meta-Analysis. J Mol Genet Med 7: 62 doi:10.4172/1747-0862.1000062

Copyright: @ 2013 Rahim F. This is an open-access article distributed under the terms of the Creative Commons Attribution License, which permits unrestricted use, distribution, and reproduction in any medium, provided the original author and source are credited 
Citation: Rahim F (2013) Diagnostic Accuracy of PCR-Based Detection Tests for Helicobacter Pylori in Otitis Media: A Meta-Analysis. J Mol Genet Med 7: 62. doi:10.4172/1747-0862.1000062

Page 2 of 4

and the information that can help infer the results, were included. Accordingly, the reviews and duplicated publications were excluded.

\section{Data extraction}

Full papers of any titles/abstracts that appeared to be relevant were obtained where possible and the relevance of each study independently was assessed according to the aforementioned inclusion and exclusion criteria.

\section{Assessment of study quality}

We measured the quality of studies using the Quality Assessment of Studies of Diagnostic Accuracy Approach-QUADAS [24], a 14-item specifically developed tool, to judge the quality of primary studies.

\section{Statistical analysis}

The diagnostic odds ratio (DOR) and symmetric summary receiver operating characteristic (sROC) of OME-associated $H$. pylori infection, were estimated for each study. The DOR and its $95 \%$ confidence interval (CI) to each study was plotted against the number of participants for detecting any possible sample size biases. The heterogeneity was tested based on the $I$-squared values, with values less than $25 \%, 25 \%$ to $50 \%$, and greater than $50 \%$ indicating low, moderate and high heterogeneity, respectively [25]. Using the bivariate method according to Reitsma et al. [26], pooled sensitivity, specificity and 95\% confidence intervals were estimated for each diagnostic test. Publication biases were observed, using the relationship between the diagnostic odds ratio (DOR) and the effective sample size (ESS) [27]. Statistical analysis was undertaken using the program STATA 11.0 software. The Meta-Disk was used to calculate individual and pooled diagnostic OR, sensitivity, specificity, negative likelihood ratio, positive likelihood ratio [28]. $\mathrm{P}<0.05$ was considered statistically significant.

\section{Results}

From the literature searches, we included eight relevant studies compromising 259 case of OME, which study selection flow is shown in figure 1.Only two studies were stated sensitivity and specificity. Table 1 summarizes the characteristics of eight studies. The quality analysis using QUADAS tool showed that six out of eight studies (75\%) fulfilled more than seven criteria. The individual and combined sensitivity and specificity estimations for the PCR test, including all selected studies were assessed (Figure 2). Overall, sensitivity and specificity varied among studies of a given PCR test. The pooled sensitivity and

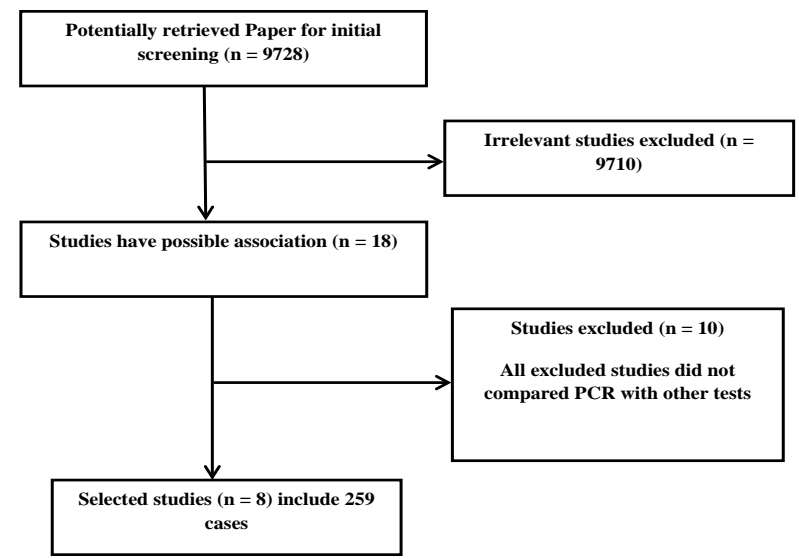

Figure 1: The flow diagram of included/excluded studies.

\begin{tabular}{|l|c|c|c|c|c|}
\hline Author, Year & Country & $\begin{array}{c}\text { Number } \\
\text { of Cases }\end{array}$ & Age & Method & HP-Positive \\
\hline$[16]$ & China & 60 & $19-73$ years & PCR & $24(40 \%)$ \\
\hline$[38]$ & Korea & 60 & $2-12$ years & PCR & $18(30 \%)$ \\
\hline$[39]$ & USA & 45 & $2-11$ years & PCR & $14(32 \%)$ \\
\hline$[40]$ & Turkey & 22 & $2-13$ years & PCR & $10(45 \%)$ \\
\hline$[41]$ & Lebanon & 18 & $3-8$ years & PCR & 0 \\
\hline$[42]$ & Turkey & 38 & $2-12$ years & PCR & $3(7.9 \%)$ \\
\hline$[43]$ & Turkey & 38 & $2-12$ years & PCR & $7(16.3 \%)$ \\
\hline$[40]$ & Turkey & 20 & $2-13$ years & PCR & $16(47 \%)$ \\
\hline
\end{tabular}

PCR, Polymerase Chain Reaction

Table 1: H. pylori infection status among OME cases included in the meta-analysis.
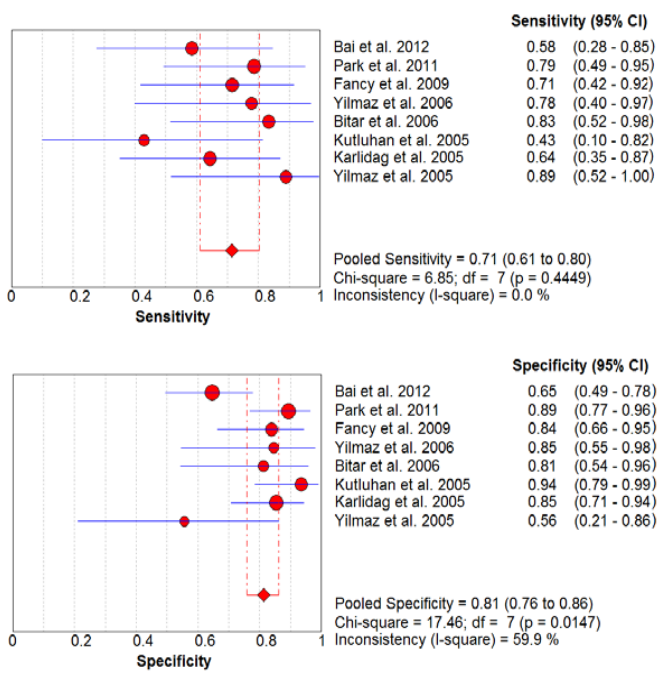

Figure 2: Estimates of sensitivity (Top) and specificity (Bottom) ( $95 \%$ confidence interval) of PCR. Combined results are shown using bothoptions: fixed and random effects model. When both results are similar with low heterogeneity, both can be used.
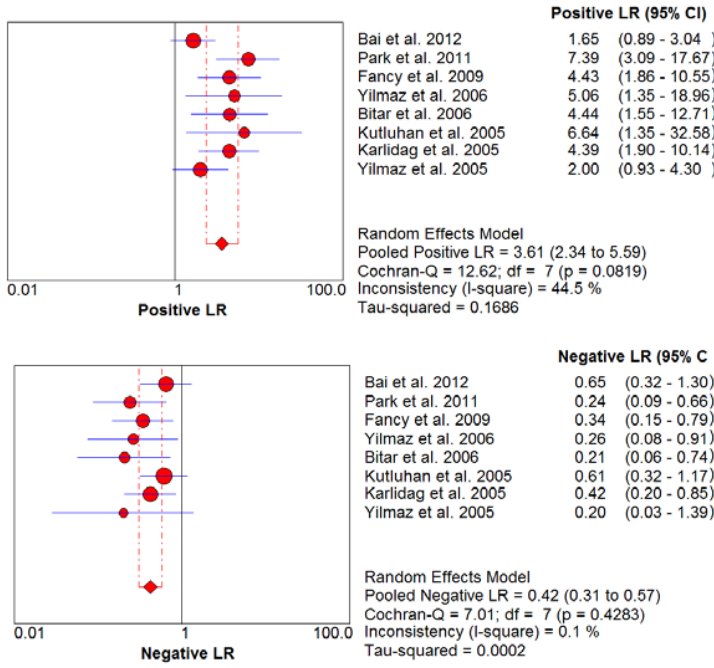

Tau-squared $=0.1686$

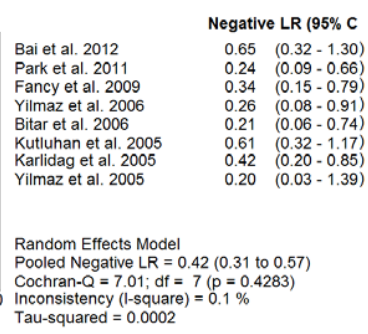

Figure 3: Estimates of positive likelihood ratio (PLR, Top) and negativelikelihood ratio (NLR, Bottom) (95\% confidence interval) of PCR. Combined results are shown using both options: fixed and random effects model. When both results are similar with low heterogeneity, both can be used. 

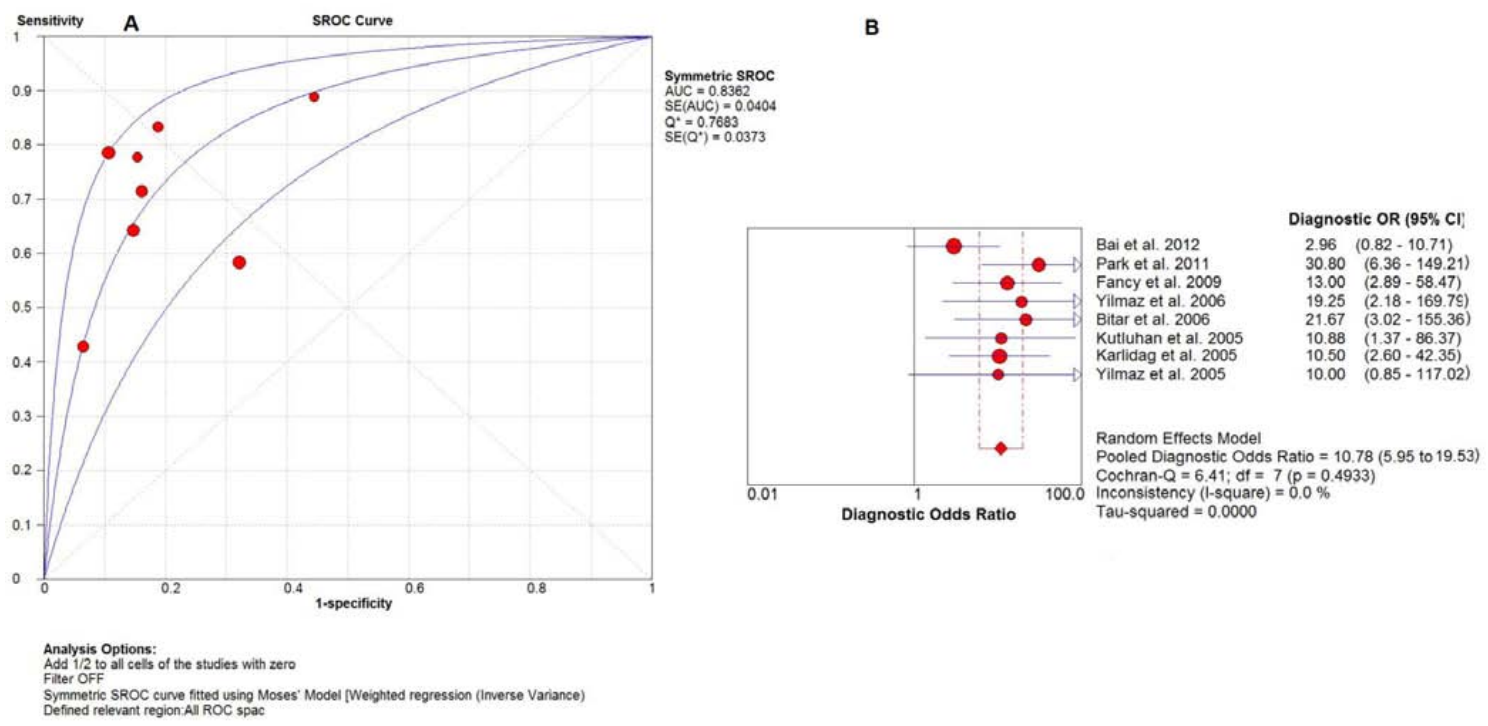

Figure 4: $\mathrm{A}, \mathrm{SROC}$ curve for $\mathrm{PCR}$ in patient with OME; B, DOR of individual and combined studies

specificity of PCR test in diagnosing $\mathrm{H}$. Pylori infection in patient with OME were $71 \%$ (95\%CI: $\left.61 \%-80 \%, \mathrm{I}^{2}: 0.0 \%\right)$ and $81 \%$ (95\%CI: $76 \%$ - 86\%,I': 59.9\%), respectively. Pooled positive likelihood ratio (PLR) and negative likelihood ratio (NLR) for PCR were 3.61(95\%CI: 2.34 - 5.59, $\left.\mathrm{I}^{2}: 44.5 \%\right)$ and 0.42 (95\%CI: $\left.0.31-0.57, \mathrm{I}^{2}: 0.1 \%\right)$, respectively (Figure 3).The sROC plots of eight selected studies and estimated DOR (95\% confidence interval) are shown in figure 4A. For DOR analysis, the pooled accuracy of PCR was 10.78 (95\%CI: $\left.5.95-19.53, \mathrm{I}^{2}: 0.0 \%\right)$ in diagnosing $H$. Pylori infection in patient with OME (Figure 4B). Egger's test 2 -sided p-value was larger than 0.05 , suggesting absence of publication bias for all tests.

\section{Discussion}

The H. Pylori infection diagnosis usually relies on the serology and histologic identification in the past [4]. However, the serology and histologic identification are not fast and reliable enough [29-33].The PCR-based molecular diagnostic techniques have been used for testing H. Pylori infections for about a decade [34,35]. Our meta-analysis revealed some concerns using the available evidences, which basically reflects the experience with PCR-based molecular diagnosis of $H$. Pylori infection among patient with OME, including the limitation of available evidences and a considerable variability among the available studies. Furthermore, the accuracy of molecular methods such as PCR is great enough, although specificity was generally high, and there is unpredictably variation in specificity among studies evaluating the same test.

Several limitations have been introduced for PCR-based molecular diagnostic, including presence false-negative and false-positive results due to the PCR inhibitors in the samples and easy contamination, and a difficulty in obtaining the worthy samples. Diagnostic accuracy of PCR may decrease at seven days after onset of the disease compared to the histologic identification and serology [36,37].

This meta-analysis addressed a moderate heterogeneity that likely was due to the differences between studies in the design (test protocol, definition of a positive result), geographical location (diverse H. Pylori infection prevalence, local strain dominance) and ethnicity (Asian and American).
This meta-analysis also showed that PCR-based molecular diagnostic method may generate consistent result with high and more variable specificity than sensitivity. Possible descriptions for these differences may include the standard control of PCR and threshold, types of the subjects and time point for sampling. Because of the absence of relative limited high quality studies and small number of published papers, this systematic review and meta-analysis have limitations, which need to be cited with cautious. Furthermore, because of only eight studies included in this review, this meta-analysis could not give strong enough evidence; thus, the findings should to be addressed in further and additional research.

\section{Conclusion}

This review showed statistically significant differences in the diagnostic accuracy between the PCR and histological tests. This metaanalysis also suggests a higher sensitivity and specificity of PCR-based molecular diagnostic method for H. Pylori infection in OME patients compared to the histological tests.

\section{References}

1. Kim N, Park RY, Cho SI, Lim SH, Lee KH, et al. (2008) Helicobacter pylor infection and development of gastric cancer in Korea: long-term follow-up. J Clin Gastroenterol 42: 448-454.

2. Sugiyama T (2004) Development of gastric cancer associated with Helicobacter pylori infection. Cancer Chemother Pharmacol 1: S12-20.

3. Uemura N (2002) The magnitude of association between Helicobacter pylor infection and the development of gastric cancer. Scand J Gastroenterol 37 869-870.

4. Calvet X, Sánchez-Delgado J, Montserrat A, Lario S, Ramírez-Lázaro MJ, et al (2009) Accuracy of diagnostic tests for Helicobacter pylori: a reappraisal. Clin Infect Dis 48: 1385-1391.

5. Koido S, Odahara S, Mitsunaga M, Aizawa M, Itoh S, et al. (2008) Diagnosis of Helicobacter pylori infection: comparison with gold standard. Rinsho Byori 56: 1007-1013.

6. Agirdir BV, Bozova S, Derin AT, Turhan M (2006) Chronic otitis media with effusion and Helicobacter pylori. Int J Pediatr Otorhinolaryngol 70: 829-834.

7. Dagli M, Eryilmaz A, Uzun A, Kayhan B, Karabulut $H$ (2006) Investigation of Helicobacter pylori in the middle ear of the patients with chronic otitis media by CLO test and $14 \mathrm{C}$ urea breath test. Otol Neurotol 27: 871-873. 
Citation: Rahim F (2013) Diagnostic Accuracy of PCR-Based Detection Tests for Helicobacter Pylori in Otitis Media: A Meta-Analysis. J Mol Genet Med 7: 62. doi:10.4172/1747-0862.1000062

8. Kara CO, Yilmaz M, Kirac S (2008) Tonsillectomy does not decrease the risk of Helicobacter pylori transmission. J Clin Gastroenterol 42: 326-327.

9. Minocha A, Raczkowski CA, Richards RJ (1997) Is a history of tonsillectomy associated with a decreased risk of Helicobacter pylori infection? J Clin Gastroenterol 25: 580-582.

10. Ozcan C, Vayisoglu Y, Otag F, Polat A, Görür K, et al. (2009) Does Helicobacter pylori have a role in the development of chronic otitis media with effusion? A preliminary study. J Otolaryngol Head Neck Surg 38: 526-531.

11. Ozdek A, Cirak MY, Samim E, Bayiz U, Safak MA, et al. (2003) A possible role of Helicobacter pylori in chronic rhinosinusitis: a preliminary report. Laryngoscope 113: 679-682.

12. Skinner LJ, Winter DC, Curran AJ, Barnes C, Kennedy S, et al. (2001) Helicobacter pylori and tonsillectomy. Clin Otolaryngol Allied Sci 26: 505-509.

13. Swarts JD, Alper CM, Luntz M, Bluestone CD, Doyle WJ, et al. (2013) Panel 2: Eustachian tube, middle ear, and mastoid--anatomy, physiology, pathophysiology, and pathogenesis. Otolaryngol Head Neck Surg 148: E26-36.

14. Chen J, Ingham N, Clare S, Raisen C, Vancollie VE, et al. (2013) Mcph1 deficient mice reveal a role for MCPH1 in otitis media. PLoS One 8: e58156.

15. Rye MS, Warrington NM, Scaman ES, Vijayasekaran S, Coates HL, et al. (2012) Genome-wide association study to identify the genetic determinants of otitis media susceptibility in childhood. PLoS One 7: e48215.

16. Bai X, Wang D, Fan Z, Han Y, Xu L, et al. (2012) Helicobacter pylori may cause otitis media with effusion: a pilot study. B-ENT 8: 261-264.

17. Saki N, Ardeshir LF, Rahim F (2013) The association of Helicobacter Pylori infection with otitis media: a meta-analysis. Archives Des Sciences 66: 452470.

18. Yilmaz T, Ceylan M, Akyön Y, Ozçakýr O, Gürsel B (2006) Helicobacter pylori: a possible association with otitis media with effusion. Otolaryngol Head Neck Surg 134: 772-777.

19. Koga $H$ (1995) The application of molecular biology to the diagnosis of mycobacteriosis. Kekkaku 70: 601-606.

20. Lagier JC, Armougom F, Million M, Hugon P, Pagnier I, et al. (2012) Microbia culturomics: paradigm shift in the human gut microbiome study. Clin Microbiol Infect 18: 1185-1193.

21. Rimbara E, Sasatsu M, Graham DY (2013) PCR detection of Helicobacter pylori in clinical samples. Methods Mol Biol 943: 279-287.

22. Saez J, Belda S, Santibáñez M, Rodríguez JC, Sola-Vera J, et al. (2012) Realtime PCR for diagnosing Helicobacter pylori infection in patients with upper gastrointestinal bleeding: comparison with other classical diagnostic methods. J Clin Microbiol 50: 3233-3237.

23. Sugimoto M, Wu JY, Abudayyeh S, Hoffman J, Brahem H, et al. (2009) Unreliability of results of PCR detection of Helicobacter pylori in clinical or environmental samples. J Clin Microbiol 47: 738-742.

24. Whiting P, Rutjes AW, Reitsma JB, Bossuyt PM, Kleijnen J (2003) The development of QUADAS: a tool for the quality assessment of studies of diagnostic accuracy included in systematic reviews. BMC Med Res Methodol 3: 25.

25. Higgins JP, Thompson SG, Deeks JJ, Altman DG (2003) Measuring inconsistency in meta-analyses. BMJ 327: 557-560.

26. Reitsma JB, Glas AS, Rutjes AW, Scholten RJ, Bossuyt PM, et al. (2005) Bivariate analysis of sensitivity and specificity produces informative summary measures in diagnostic reviews. J Clin Epidemiol 58: 982-990.

27. Deeks JJ, Macaskill P, Irwig L (2005) The performance of tests of publication bias and other sample size effects in systematic reviews of diagnostic test accuracy was assessed. J Clin Epidemiol 58: 882-893.

28. Zamora J, Abraira V, Muriel A, Khan K, Coomarasamy A ( 2006) Meta-DiSc: a software for meta-analysis of test accuracy data. BMC Med Res Methodol 6: 31.
29. Al-Attas SG, Shehata MI, Esmaeal HM, Radhwan NA (2010) Prognostic value of quantitative-PCR versus serology for detection of CMV in pre- and posttransplantation patients. Egypt J Immunol 17: 41-48.

30. Haaheim H, Vorland L, Gutteberg TJ (2001) Laboratory diagnosis of respiratory diseases: PCR versus serology. Nucleosides Nucleotides Nucleic Acids 20 1255-1258.

31. Otten HG, Tilanus MG, Barnstijn M, van Heugten JG, de Gast GC (1995) Serology versus PCR-SSP in typing for HLA-DR and HLA-DQ: a practical evaluation. Tissue Antigens 45: 36-40.

32. Usichenko T, Lattermann A, Mueller-Eckhardt G (1998) Serology versus ARMS-PCR in prospective HLA-class I typing for bone marrow transplantation. Ann Hematol 77: 97-100.

33. Zhang L, Zong ZY, Liu YB, Ye H, Lv XJ (2011) PCR versus serology for diagnosing Mycoplasma pneumoniae infection: a systematic review \& metaanalysis. Indian J Med Res 134: 270-280.

34. Harper CG, Whary MT, Feng Y, Rhinehart HL, Wells RS, et al. (2003) Comparison of diagnostic techniques for Helicobacter cetorum infection in wild Atlantic bottlenose dolphins (Tursiops truncatus). J Clin Microbiol 41: 2842 2848

35. LEHOURS P, SIFFRE E, MEGRAUD F (2011) DPO multiplex PCR as an alternative to culture and susceptibility testing to detect Helicobacter pylori and its resistance to clarithromycin. BMC Gastroenterol 11: 112

36. Gutiérrez S, Chacón-Petrola M, Flores M, Pinto A, Pacheco M (2005) Evaluation of infection by Helicobacter pylori in HIV positive patients trough enzyme immunoassay and specific amplification of DNA. Invest Clin 46: 43-52.

37. Wang JT, Lin JT, Sheu JC, Yang JC, Chen DS, et al. (1993) Detection of Helicobacter pylori in gastric biopsy tissue by polymerase chain reaction. Eur $\mathrm{J}$ Clin Microbiol Infect Dis 12: 367-371.

38. Park CW, Chung JH, Min HJ, Kim KR, Tae K, et al. (2011) Helicobacter pylor in middle ear of children with otitis media with effusion. Chin Med J (Engl) 124 4275-4278.

39. Fancy T, Mathers PH, Ramadan HH (2009) Otitis media with effusion: a possible role for Helicobacter pylori? Otolaryngol Head Neck Surg 140: 256258.

40. Yilmaz MD, Aktepe O, Cetinkol Y, Altuntas A (2005) Does Helicobacte pylori have role in development of otitis media with effusion? Int J Pediatr Otorhinolaryngol 69: 745-749.

41. Bitar M, Mahfouz R, Soweid A, Racoubian E, Ghasham M, et al. (2006) Does Helicobacter pylori colonize the nasopharynx of children and contribute to their middle ear disease? Acta Otolaryngol 126: 154-159.

42. Kutluhan A, Yurttaş V, Akarca US, Aydn A, Tuncer I, et al. (2005) Possible role of Helicobacter pylori in the etiopathogenesis of chronic otitis media. Otol Neurotol 26: 1125-1127.

43. Karlidag T, Bulut Y, Keles E, Kaygusuz I, Yalcin S, et al. (2005) Detection of Helicobacter pylori in children with otitis media with effusion: a preliminary report. Laryngoscope 115: 1262-1265. 